\title{
Ob/Gyn resident self-perceived preparedness for minimally invasive surgery
}

Jordan S. Klebanoff ${ }^{1 *}$ (D), Cherie Q. Marfori ${ }^{1}$, Maria V. Vargas ${ }^{1}$, Richard L. Amdur ${ }^{2}$, Catherine Z. Wu ${ }^{1}$ and Gaby N. Moawad ${ }^{1}$

\begin{abstract}
Background: Very little is known regarding the readiness of senior U.S. Ob/Gyn residents to perform minimally invasive surgery. This study aims to evaluate the self-perceived readiness of senior Ob/Gyn residents to perform complex minimally invasive gynecologic surgery as well as their perceptions of the minimally invasive gynecologic surgery subspecialty.

Methods: We performed a national survey study of 3rd and 4th year Ob/Gyn residents. A novel 58-item survey was developed and sent to residency program directors and coordinators with the request to forward the survey link along to their senior residents.

Results: We received 158 survey responses with 84 (53.2\%) responses coming from 4th year residents and 74 (46.8\%) responses from $3 r d$ year residents. Residents who train with graduates of a fellowship in minimally invasive gynecologic surgery felt significantly more prepared to perform minimally invasive surgery compared to residents without this exposure in their training. The majority of senior residents (71.5\%) feel their residency training adequately prepared them to be a competent minimally invasive gynecologic surgeon. However, only $50 \%$ feel prepared to perform a laparoscopic hysterectomy on a uterus greater than 12 weeks size, 29\% feel prepared to offer a vaginal hysterectomy on a uterus 12 -week size or greater, $17 \%$ feel comfortable performing a laparoscopic myomectomy, and 12\% feel prepared to offer a laparoscopic hysterectomy for a uterus above the umbilicus.

Conclusions: The majority of senior U.S. Ob/Gyn residents feel prepared to provide minimally invasive surgery for complex gynecologic cases. However, surgical confidence in specific procedures decreases when surgical complexity increases.
\end{abstract}

Keywords: Gynecology, Minimally invasive gynecologic surgery, Surgery, Surgical education, Residency

\footnotetext{
* Correspondence: Jsk5068@gmail.com

'Department of Obstetrics and Gynecology, The George Washington

University School of Medicine and Health Sciences, Washington, D.C, USA

Full list of author information is available at the end of the article
}

(c) The Author(s). 2020 Open Access This article is licensed under a Creative Commons Attribution 4.0 International License, which permits use, sharing, adaptation, distribution and reproduction in any medium or format, as long as you give appropriate credit to the original author(s) and the source, provide a link to the Creative Commons licence, and indicate if changes were made. The images or other third party material in this article are included in the article's Creative Commons licence, unless indicated otherwise in a credit line to the material. If material is not included in the article's Creative Commons licence and your intended use is not permitted by statutory regulation or exceeds the permitted use, you will need to obtain permission directly from the copyright holder. To view a copy of this licence, visit http://creativecommons.org/licenses/by/4.0/ The Creative Commons Public Domain Dedication waiver (http://creativecommons.org/publicdomain/zero/1.0/) applies to the data made available in this article, unless otherwise stated in a credit line to the data. 


\section{Highlights}

- The majority of senior US Ob/Gyn residents have self perceived preparedness to perform minimally invasive surgery

- As surgical procedures become increasingly complex resident self perceived preparedness to perform these procedures decreases

- Senior Ob/Gyn residents are least confident in performing vaginal hysterectomies requiring vaginal morcellation for tissue extraction, laparoscopic hysterectomies when the uterus is above the umbilicus, excision of stage 3 or 4 endometriosis, laparoscopic myomectomies requiring suturing, and laparoscopic myomectomies requiring suturing of more than one hysterotomy

- Residents who train with graduates of a fellowship in MIGS felt significantly more prepared to perform MIGS compared to residents without this exposure in their training

\section{Background}

There is a growing concern that the traditional 4-year Ob/Gyn residency does not allow enough time for comprehensive surgical training. Restricted resident duty hours and increased medical management of gynecologic conditions result in lower surgical caseloads among graduates $[1,2]$. A national conversation of whether or not "tracking," which allows for increased clinical time in specific areas of interest based on resident preference, should be an option within U.S. Ob/Gyn residencies is underway [3]. At least 1 U.S. program is already incorporating this practice into their training [4]. Supporters of "tracking" believe that the typical 18 months throughout a typical 48-month residency program spent focused on gynecologic surgery is too little for comprehensive training [2]. Surgical training and resident exposure are of utmost importance as data continually demonstrates that volume matters; surgical morbidity is reduced when gynecologic surgery is performed by high volume surgeons [5-7]. Subspecialty training may be the only option to counteract this perceived deficiency in our traditional training model.

Less than half of first year fellows in 4 different subspecialties within Ob/Gyn (FPMRS, Onc, REI, and MFM) were considered prepared to function independently by their fellowship directors [8]. Active and former minimally invasive surgery fellows state one main reason for pursuing fellowship after completing a general surgery residency is to improve their surgical skills [9]. However, little is known about senior Ob/Gyn residents' own perceptions of their preparedness to perform MIGS. Even less is known about the readiness of senior $\mathrm{Ob} /$ Gyn residents to perform both basic and complex MIGS.
Recently the ACGME increased the minimum graduating requirement for minimally invasive hysterectomies from 35 to 70 [10]. With the calls to increase utilization of minimally invasive surgery undoubtedly more and more complex gynecologic cases will be attempted laparoscopically or vaginally $[11,12]$. However, are we asking too much of undertrained and underprepared gynecologic surgeons? The aim of this study is to evaluate the confidence of senior U.S. Ob/Gyn residents in performing MIGS. Furthermore, we stratified this data by their intentions to pursue a surgical subspecialty fellowship (ONC, MIGS, FPMRS, REI, and PAGS) to determine if residents pursuing fellowship had differing levels of comfort with MIGS.

\section{Methods}

We created and administered a voluntary survey for current U.S. Ob/Gyn residents using the Research Electronic Data Capture (REDCap) secure online platform. All study data were collected and managed using the REDCap tools hosted by The George Washington University $[13,14]$. Because participation in this study was voluntary and information was kept de-identified, this study was determined to be exempt by the Institutional Review Board (IRB\# 180767). Current U.S. accredited $\mathrm{Ob} /$ Gyn residency programs were identified using the ACGME online data system [15]. Program coordinators as well as program directors were contacted via email using publicly available information through the ACGME website. Throughout the months of February and March of 2019 program coordinators as well as program directors for all 280 registered Ob/Gyn residency programs (representing 5598 active Ob/Gyn residents) received a cover letter email including an electronic link to the survey and were asked to forward this link along to their residents. This email request was sent on three separate occasions over this two-month period in an effort to maximize the response rate. Resident responses to the survey were no longer accepted after June 1, 2019, which allowed a full 3 months for all interested residents to participate.

Because a validated survey assessing senior Ob/Gyn resident confidence in performing MIGS does not exist, all of the listed authors took part in creating a novel 58item survey (Supplemental Figure 2). These authors included two fellows in MIGS, three MIGS fellowship trained high-volume surgeons from a single center, and one statistician. The authors did not employ any specific methodology to create the survey and questions were created and approved based on overall consensus. Senior $\mathrm{Ob} / \mathrm{Gyn}$ residents were defined as residents in either the third or fourth year of residency. The survey contained basic demographic questions as well as questions designed to assess resident confidence in specific 
gynecologic procedures using a Likert scale from 1 to 5 ( $1=$ Strongly Agree, $5=$ Strongly Disagree). Additionally, some procedural questions were repeated with differing levels of complexity. For instance, confidence in laparoscopic hysterectomy was queried for a uterus less than 12-weeks size, greater than 12-week size but below the umbilicus, and for a uterus above the umbilicus. Similar question trees were designed to assess confidence in vaginal hysterectomy, laparoscopic myomectomy, hysteroscopic myomectomy, excision of endometriosis, specimen containment, tissue morcellation, and navigating the robotic surgical console. Residents were able to initiate the survey and finish at a later time, however, other than for demographic questions surveys could not be submitted with missing answer fields. If surveys returned had missing answer fields these fields were censored in the analysis. Chi-square or Fisher's exact tests were used to examine associations between categorical variables, and 2-tailed between-groups t-tests were used to examine differences in means across groups. We used SAS 9.4 (SAS Institute, Cary, NC) for all analyses and a $P$ value $<0.05$ was considered statistically significant.

\section{Results}

We received 328 survey responses, 159 (48.5\%) of which were from senior $\mathrm{Ob} / \mathrm{Gyn}$ residents and included in the final analysis. Assuming all $5598 \mathrm{Ob} / \mathrm{Gyn}$ residents were given the opportunity to participate this yields an approximate $6 \%$ response rate for senior $\mathrm{Ob} / \mathrm{Gyn}$ residents (159/2799). Basic demographic information as well as details regarding respondents residency programs are outlined in Table 1 . Overall $76.2 \%$ of respondents felt that their residency program has adequately prepared them to perform MIGS. Residents who train with graduates of a fellowship in MIGS, regardless of whether or not the institution has a MIGS fellowship program, felt significantly more prepared to perform MIGS compared to residents without this exposure in their training ( $p=$ 0.02). Training environments including academic institutions, community programs, and academic-affiliated community programs did not have a significant impact on resident preparedness for MIGS $(p=0.44)$. There were no other statistically significant background differences found between residents who feel prepared to perform minimally invasive surgery and those that do not (Table 2).

We did identify certain trends across procedures with respondents feeling less comfortable performing specific gynecologic procedures as the surgical complexity increased (Figs. 1a and b). Eighty-two percent of respondents felt confident in their ability to perform a total laparoscopic hysterectomy on a uterus less than 12-week size, however, this percent decreases to $13.4 \%$ when the uterus is above the umbilicus. Only $18 \%$ of respondents
Table 1 Demographic and background variables

\begin{tabular}{|c|c|}
\hline Variable & Senior Residents $(\boldsymbol{N}=159)$ \\
\hline \multicolumn{2}{|l|}{ Year in Residency } \\
\hline Third & $74(46.5)$ \\
\hline Fourth & $85(53.5)$ \\
\hline \multicolumn{2}{|l|}{ Medical Degree } \\
\hline Allopathic & $140(88.1)$ \\
\hline Osteopathic & 19 (11.9) \\
\hline \multicolumn{2}{|l|}{ Gender } \\
\hline Female & $130(81.8)$ \\
\hline Male & $28(17.6)$ \\
\hline \multicolumn{2}{|l|}{ Race } \\
\hline White/Caucasian & $105(66.5)$ \\
\hline Black or African-American & $13(8.2)$ \\
\hline Asian & $25(15.8)$ \\
\hline From Multiple Races & $2(1.3)$ \\
\hline Age Between 26 and 30 & $90(56.6)$ \\
\hline \multicolumn{2}{|l|}{ Residency Training Type } \\
\hline Academic & $96(60.4)$ \\
\hline Community & $17(10.7)$ \\
\hline Community-Academic Affiliated & $46(28.9)$ \\
\hline \multicolumn{2}{|l|}{ Geographic Region of Training } \\
\hline North East & $75(47.5)$ \\
\hline North West & $14(8.9)$ \\
\hline South East & $49(31.0)$ \\
\hline South West & $20(12.6)$ \\
\hline Feel Prepared to Perform MIGS & $114(76.19)$ \\
\hline \multicolumn{2}{|c|}{ Applying for, or Accepted in, a Surgical Fellowship ${ }^{a}$} \\
\hline Yes & $40(25.2)$ \\
\hline No & $108(67.9)$ \\
\hline \multicolumn{2}{|c|}{ Work in an Institution with Graduate(s) of a MIGS Fellowship } \\
\hline Yes & $93(58.5)$ \\
\hline No & $64(40.3)$ \\
\hline Feel Prepared to Perform MIGS & $114(76.19)$ \\
\hline
\end{tabular}

felt comfortable performing a laparoscopic myomectomy and this rate decreased to $13 \%$ if the procedure required more than one hysterotomy. Although the purpose of this study was not to assess junior residents (Ob/Gyn residents in either their first or second year) it is interesting to note the validation of our novel survey. Only $17.2 \%$ of junior residents felt confident in their ability to perform a total laparoscopic hysterectomy on a uterus less than 12-week size (compared to $82 \%$ for senior residents), and this percent drops to $5 \%$ when the uterus is 
Table 2 Characteristics of senior residents who feel their residency training has adequately prepared them to perform Minimally Invasive Gynecologic Surgery $(N=159)$

\begin{tabular}{|c|c|c|}
\hline Variable & Mean Likert Score & $P$-Value \\
\hline Year in Residency & & 0.36 \\
\hline Third & $2.21 \pm 0.85$ & \\
\hline Fourth & $2.08 \pm 0.91$ & \\
\hline Medical Degree & & 0.33 \\
\hline Allopathic & $2.16 \pm 0.90$ & \\
\hline Osteopathic & $1.94 \pm 0.75$ & \\
\hline \multicolumn{3}{|l|}{ Race } \\
\hline White/Caucasian & $2.05 \pm 0.91$ & 0.10 \\
\hline Black/African-American & $2.00 \pm 0.63$ & 0.60 \\
\hline Asian & $2.43 \pm 0.73$ & 0.08 \\
\hline Gender & & 0.98 \\
\hline Female & $2.14 \pm 0.86$ & \\
\hline Male & $2.12 \pm 0.99$ & \\
\hline Age & & 0.27 \\
\hline $26-30$ & $2.07 \pm 0.90$ & \\
\hline $31-35$ & $2.20 \pm 0.77$ & \\
\hline$>35$ & $3.00 \pm 2.83$ & \\
\hline Type of Residency Program & & 0.44 \\
\hline Academic & $2.16 \pm 0.94$ & \\
\hline Community & $1.88 \pm 0.89$ & \\
\hline Community-Academic Affiliated & $2.20 \pm 0.75$ & \\
\hline Work with Graduate(s) of MIGS Fellowship & & 0.02 \\
\hline Yes & $2.00 \pm 0.81$ & \\
\hline No & $2.39 \pm 0.94$ & \\
\hline
\end{tabular}

Values reported as mean \pm SD on a 5 -point Likert Scale $(1=$ Strongly Agree and $5=$ Strongly Disagree)

$P<0.05$ Bold

above the umbilicus. Only 5.7\% of junior residents felt comfortable performing a laparoscopic myomectomy and this rate decreased to $4.1 \%$ if more than one hysterotomy was required.

Using respondents mean Likert scale scores we identified the 5 procedures residents are least confident in performing as: 1) vaginal hysterectomy requiring vaginal morcellation for tissue extraction; 2) laparoscopic hysterectomy when the uterus is above the umbilicus; 3) excision of stage 3 or 4 endometriosis; 4) laparoscopic myomectomy requiring suturing; and 5) laparoscopic myomectomy requiring suturing of more than one hysterotomy. We found that the respondents who felt most confident (top 35th percentile) in performing these 5 most challenging procedures were significantly more likely to identify as male $(p=0.04)$. There is a nonsignificant trend towards higher confidence in the most challenging procedures among residents exposed to fellowship trained MIGS faculty $(p=0.08)$. No other statistically significant demographic or educational differences were identified between respondents who felt the most confident in performing the most challenging procedures and those who felt less confident (Table 3).

We identified certain significant differences between residents who responded that they were either interested in, or had matched into, any one of the five surgical subspecialties of Ob/Gyn compared to residents that were not. Residents interested in surgical fellowships were more likely to be male $(p=0.005)$, train in an institution with both a division of MIGS $(p=0.02)$ and a MIGS fellowship program $(p=0.001)$, as well as train in an institution with a fellowship in FPMRS $(p=0.004)$. Overall, only $52.7 \%$ of respondents consider MIGS a subspecialty of Ob/Gyn in the same way they consider other accredited surgical subspecialties of Ob/Gyn (ONC, FPMRS, and REI). Less than half of the respondents not pursuing a fellowship (47.3\%) plan on referring their complex gynecologic surgeries to a fellowship trained MIGS surgeon after completing their training. Resident confidence level in the most challenging surgical procedures had a trend-level association with their intentions to refer these procedures to a fellowship trained MIGS surgeon $(p=0.06)$.

\section{Discussion}

We found that the majority of senior U.S Ob/Gyn residents who responded to this survey feel their training has prepared them to perform minimally invasive surgery. However, surgical confidence in specific procedures decreased when surgical complexity increased. Those residents exposed to fellowship trained MIGS surgeons appear to feel more prepared for minimally invasive surgery compared to residents lacking this exposure. One possible explanation for this is that residents in programs with MIGS fellowships complete a higher percentage of their cases, both simple and complex, through minimally invasive routes; thus the resident is exposed and has more confidence with these procedures.

With growing interest in the MIGS fellowship in MIGS and yearly increases in fellowship programs across the country, this should serve to increase resident comfort with MIGS [16]. In a similar study of 4th year U.S. $\mathrm{Ob} / \mathrm{Gyn}$ residents, the data show that exposure to laparoscopic simulation (box trainers), as well as didactic lectures and a formal skills assessment were associated with perceived laparoscopic competence [17]. The impact of exposure to fellowship trained MIGS faculty was not assessed in that study. However, a different study by the same author did find that establishment of a MIGS fellowship at a single academic institution had a positive overall effect on resident experience and attitude without compromising surgical numbers [18]. 
A - Percent of confident senior residents in performing a total laparoscopic hysterectomy (TLH) across increasing complexity determined by the size of the uterus (wks)

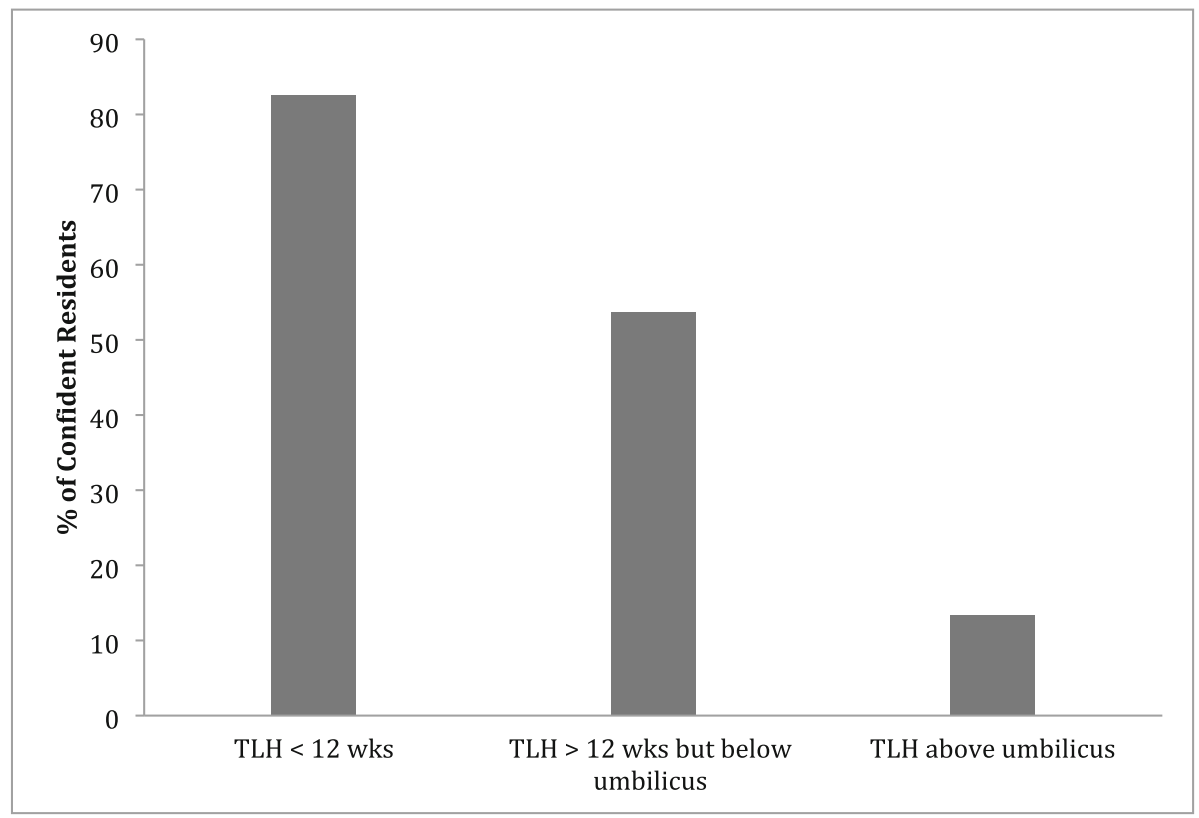

B - Percent of confident senior residents in performing total vaginal hysterectomy (TVH) across increasing complexity based on size of the uterus (wks) and surgical history

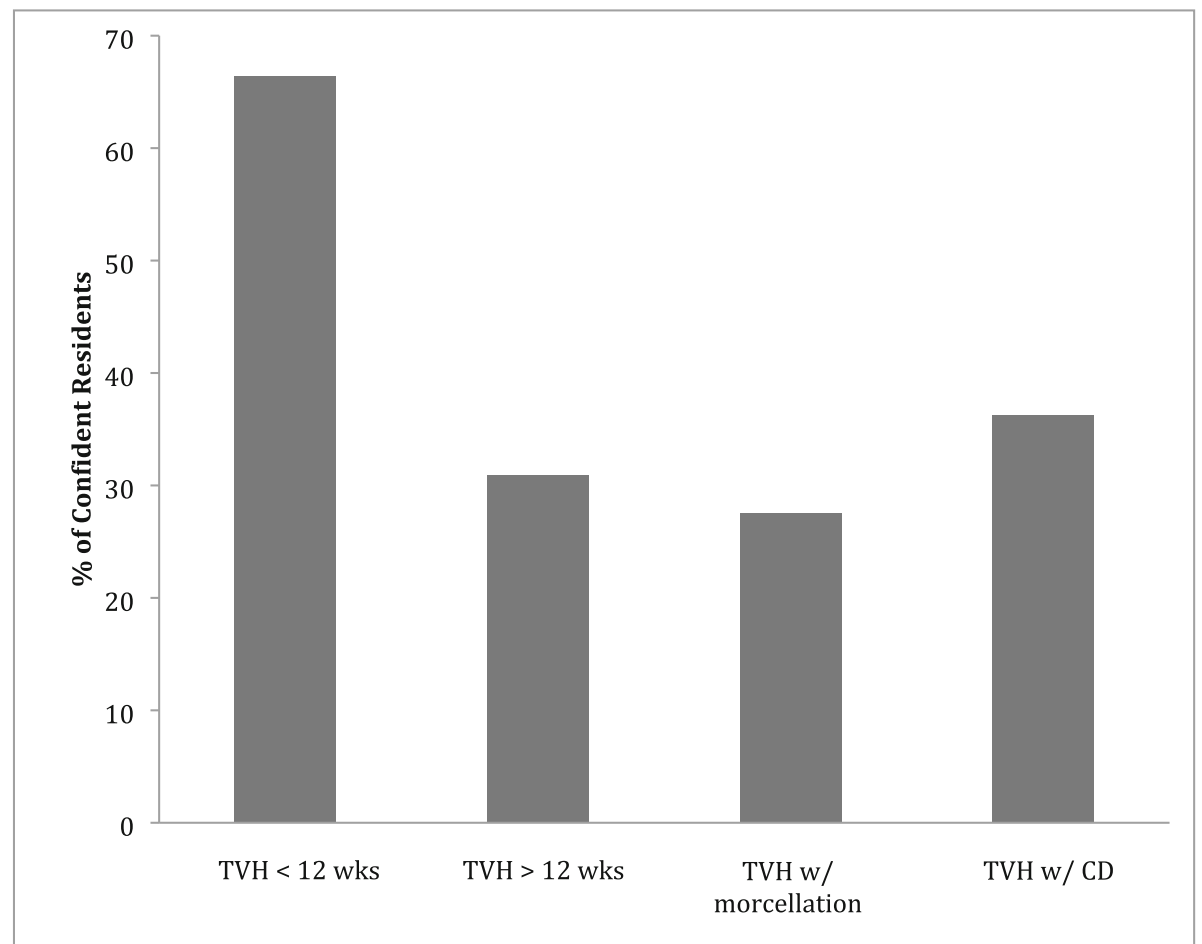

Total vaginal hysterectomy requiring morcellation for tissue extraction (TVH w/ morcellation), Total vaginal hysterectomy for a patient with a history of one or more cesarean deliveries (TVH w/ CD)

Fig. 1 a Trends in Ob/Gyn senior resident confidence in total laparoscopic hysterectomy as surgical complexity increases. b Trends in Ob/Gyn senior resident confidence in total vaginal hysterectomy as surgical complexity increases 
Table 3 Characteristics of the residents most confident in their ability to perform the most challenging minimally invasive surgeries

\begin{tabular}{|c|c|c|c|}
\hline Variable & $\begin{array}{l}\text { Most Confident Residents } \\
(\boldsymbol{N}=56)\end{array}$ & $\begin{array}{l}\text { Less Confident Residents } \\
(\boldsymbol{N}=103)\end{array}$ & $P$-Value \\
\hline Year in Residency & & & 0.32 \\
\hline Third & $23(31.1)$ & $51(68.9)$ & \\
\hline Fourth & $33(38.8)$ & $52(61.2)$ & \\
\hline Medical Degree & & & 0.61 \\
\hline Allopathic & $48(34.3)$ & $92(65.7)$ & \\
\hline Osteopathic & $8(42.1)$ & $11(57.9)$ & \\
\hline Race & & & 0.60 \\
\hline White/Caucasian & $39(37.1)$ & $66(62.9)$ & \\
\hline Black/African-American & $7(53.9)$ & $6(46.1)$ & \\
\hline Asian & $6(24.0)$ & $19(76.0)$ & \\
\hline Gender & & & 0.04 \\
\hline Female & $41(31.5)$ & $89(68.5)$ & \\
\hline Male & $15(53.6)$ & $13(46.4)$ & \\
\hline Type of Residency Program & & & 0.44 \\
\hline Academic & $31(32.3)$ & $65(67.7)$ & \\
\hline Community & $8(47.1)$ & $9(52.9)$ & \\
\hline Community-Academic Affiliated & $17(37.0)$ & $29(63.0)$ & \\
\hline Work with Graduate(s) of MIGS Fellowship & & & 0.08 \\
\hline Yes & $29(31.2)$ & $64(68.8)$ & \\
\hline No & $25(39.1)$ & $39(60.9)$ & \\
\hline Intend to Pursue, or Matched in, a Surgical Fellowship & & & 0.09 \\
\hline Yes & $16(40.0)$ & $24(60.0)$ & \\
\hline No & $40(37.0)$ & $68(63.0)$ & \\
\hline
\end{tabular}

Values reported as $\mathrm{n}(\%)$. Not all variables represented; not all cumulative $n=159$ $P<0.05$ bold

A significantly larger proportion of respondents who were more confident in performing the 5 most challenging procedures identified as male. This finding is consistent with previously published data showing male residents were significantly more confident in performing total hysterectomy and treating endometriosis [17]. This finding likely reflects the disparity that exists between male and female surgical training. Previous study has found that male surgical trainees are given more autonomy in the operating room compared to their female counterparts [19]. No other background or educational variables appear to impact resident preparedness for complex minimally invasive surgery. There was no significant difference in surgical confidence between residents pursuing any of the surgical fellowships in $\mathrm{Ob} /$ Gyn and those residents planning on entering into general practice. Previous studies have found that less than half of fellowship program directors feel that their incoming fellows are "prepared" for fellowship $[8,20]$. Specifically, fellowship program directors do not feel their fellows enter their subspecialty of training with adequate procedural skills to function independently $[8,20]$.
However, fellows own perceptions differ from their program directors; with a majority of fellows feeling their residency did prepare them for fellowship [21]. Data from General Surgery has shown that one of the main reasons residents pursue a fellowship in minimally invasive surgery is to increase their laparoscopic skills [9]. However, this study did not find that residents pursuing a fellowship in MIGS were any more or less confident in their surgical skills compared to those residents pursuing any other surgical fellowship or those residents not pursuing a fellowship.

Despite a majority of respondents own perceived confidence in MIGS there appears to be an inconsistency regarding complex gynecologic procedures. Fewer than one in five respondents feel confident in their ability to perform a laparoscopic myomectomy, a total laparoscopic hysterectomy for a uterus above the umbilicus, and a laparoscopic excision of advanced stage endometriosis. More concerning is the lack of intent to refer these complex cases to a fellowship trained MIGS surgeon if available. One possible, albeit worrying, explanation for this may be that these residents do not realize that these complex cases can be safely completed 
laparoscopically [22, 23]. Currently, no required case minimums exist for laparoscopic excision of endometriosis or laparoscopic myomectomy [10]. Residents are now required to perform a minimum of 70 minimally invasive hysterectomies, however, no system exists to account for the complexity of these minimally invasive cases [10]. Future study should aim to identify the mode of surgery and associated outcomes of these complex surgical patients not being referred to MIGS surgeons by recently graduated Ob/Gyns.

This study is not without its limitations. Unfortunately, there was a low resident participation rate and outreach was limited, as U.S. Ob/Gyn residents cannot be contacted directly through any publicly available database. According to the ACGME website during this study period there were 5598 active duty Ob/Gyn residents. However, we do not know how many of the 5598 were senior residents and there is also unfortunately no way to track how many senior Ob/Gyn residents were sent the survey link by their program. This also creates potential bias as we cannot assume the reasons certain program coordinators or directors would not forward this survey on to their senior residents. This low participation rate limits the generalizability of these results and likely results in this study being underpowered to identify potential significant differences. There is also an unavoidable selection bias inherent in the nature of this study. We relied on a 58-item survey that all authors had a part in creating as there is no validated survey to assess resident confidence in performing MIGS. Confidence in surgical procedures is also very subjective and does not necessarily equate to ability in performing the procedure. Strengths of this study come from the diversity of participants in terms of identified sex, geographic location, and residency type.

\section{Conclusions}

To our knowledge this is also the first study to assess confidence in a variety of surgical procedures with question trees to simulate increasing surgical complexity. We also highlight 5 procedures residents are the least confident in performing and assess other indirect surgical skills underrepresented in the available literature. This data should serve as a guide for residency program directors, fellowship directors, and the ACGME, highlighting residents own perceived surgical deficiencies. Our findings stress the issue of whether case minimum numbers should be considered for certain complex procedures such as laparoscopic myomectomy and excision of endometriosis. Additionally, experience level should be taken into consideration when surgical credentialing privileges are being granted by institutions after graduation. Further study should target how to improve resident exposure and confidence in the procedures felt to be the most challenging.

\section{Supplementary information}

Supplementary information accompanies this paper at https://doi.org/10. 1186/s12909-020-02090-9.

Additional file 1: Supplemental Figure S2. Resident survey.

\section{Abbreviations}

MIGS: Minimally Invasive Gynecologic Surgery; Ob/Gyn: Obstetrics and Gynecology; FPMRS: Female Pelvic Medicine and Reconstructive Surgery; Onc: Gynecologic Oncology; MFM: Maternal Fetal Medicine;

REl: Reproductive Endocrinology \& Infertility; PAGS: Pediatric and Adolescent Gynecology; ACGME: Accreditation Council for Graduate Medical Education

\section{Acknowledgments}

The authors would like to thank all of the U.S Ob/Gyn residents who took the time to participate in this study.

\section{Disclosure}

Drs. Klebanoff, Marfori, Vargas, Amdur, and Wu have nothing to declare. Dr. Moawad is a consultant for Intuitive Surgical.

\section{Authors' contributions}

All authors played an integral role in study conception, as well as study design and survey development. Specifically, JSK, CQM, MW, CZW, RLA, and GNM participated in study design, creation of the study survey, dissemination of the survey, interpretation of the data, and manuscript writing as well as editing. Specifically, RLA performed all of the data analysis for this study. All authors have agreed to be personally accountable for their own contributions and ensure the accuracy and integrity of all parts of the work.

\section{Funding}

This study did not require any funding.

\section{Availability of data and materials}

All materials utilized in this study as well as available datasets can be produced and are available with reasonable request.

\section{Ethics approval and consent to participate}

This study was determined to be exempt by The George Washington University Committee on Human Research, Institutional Review Board (IRB \#180767; Reference \# FWA00005945). All participants gave voluntary consent to participate in this electronic survey study.

Consent for publication

Not applicable.

\section{Competing interests}

No authors have any competing interests to disclose.

\section{Author details}

${ }^{1}$ Department of Obstetrics and Gynecology, The George Washington University School of Medicine and Health Sciences, Washington, D.C, USA. ${ }^{2}$ Department of Surgery, The George Washington University School of Medicine and Health Sciences, Washington, D.C, USA.

Received: 9 March 2020 Accepted: 25 May 2020

Published online: 05 June 2020

References

1. Kho RM. Fellowship in minimally invasive gynecologic surgery: the evolving field behind the name. J Minim Invasive Gynecol. 2018;25(7):1115-6.

2. Glaser LM, Brennan L, King LP, Milad MP. Surgeon volume in benign gynecologic surgery: review of outcomes, impact on training, and ethical contexts. J Minim Invasive Gynecol. 2019;26(2):279-87.

3. Anderson TL. We are the champions of Women's health care. Obstet Gynecol. 2019;134(1):1-3

4. Gutman RE, Morgan D, Levy B, Kho RM, Mansuria S. How can we improve the percentage and quality of minimally invasive hysterectomy for benign disease among low/intermediate-volume gynecologic surgeons? a perspective piece from an expert panel session at the 2017 society of 
gynecologic surgeons annual meeting. J Minim Invasive Gynecol. 2017; 24(7):1055-9.

5. McDonnell RM, Hollingworth JL, Chivers P, Cohen PA, Salfinger SG. Advanced training of gynecologic surgeons and incidence of intraoperative complications after Total laparoscopic hysterectomy: a retrospective study of more than 2000 cases at a single institution. J Minim Invasive Gynecol. 2018;25(5):810-5.

6. Ruiz MP, Chen L, Hou JY, Tergas Al, et al. Outcomes of hysterectomy performed by very low-volume surgeons. Obstet Gynecol. 2018;131(6):981-90.

7. Boyd LR, Novetsky AP, Curtin JP. Effect of surgical volume on route of hysterectomy and short-term morbidity. Obstet Gynecol. 2010;116(4):909-15.

8. Guntupalli SR, Doo DW, Guy M, Sheeder J, et al. Preparedness of obstetrics and gynecology residents for fellowship training. Obstet Gynecol. 2015; 126(3):559-68.

9. Watkins JR, Pryor AD, Truitt MS, Jeyarajah RD. Perception versus reality: elucidating motivation and expectations of current fellowship council minimally invasive surgery fellows. Surg Endosc. 2018;32(11):4422-7. https:// doi.org/10.1007/s00464-018-6184-2.

10. "Minimum Numbers: Obstetrics and Gynecology." ACGME, Accreditation Council for Graduate Medical Education Review Committee for Obsterics and Gynecology, www.acgme.org/Specialties/Documents-and-Resources/ pfcatid/12/Obstetrics_and_Gynecology. Accessed 4 Jan 2019.

11. Committee on Gynecologic Practice. Committee opinion no. 701: choosing the route of hysterectomy for benign disease. Obstet Gynecol. 2017;129: 3155-9.

12. AAGL. Position statement: route of hysterectomy to treat benign uterine disease. J Minim Invasive Gynecol. 2011;18(1):1-3. https://doi.org/10.1016/j. jmig.2010.10.001.

13. Harris PA, Taylor R, Thielke R, Payne J, Gonzalez N, Conde JG. Research electronic data capture (REDCap) - a metadata-driven methodology and workflow process for providing translational research informatics support. J Biomed Inform. 2009;42(2):377-81.

14. Harris PA, Taylor R, Minor BL, Elliott V, Fernandez M, O'Neal L, McLeod L, Delacqua G, Delacqua F, Kirby J, Duda SN, REDCap Consortium. The REDCap consortium: Building an international community of software partners. J Biomed Inform. 2019. https://doi.org/10.1016/j.jbi.2019.103208.

15. "Data Collection Systems." ACGME, www.acgme.org/Data-CollectionSystems/Overview. Accessed 11 Jan 2019.

16. Vargas MV, Magdy MP. Matching trends for the fellowship in minimally invasive gynecologic surgery since participation in the National Residency Match Program. J Minimal Invasive Gynecol. 2018;25(6):1060-4.

17. Einarsson Jl, Sangi-Haghpeykar H. Perceived proficiency in minimally invasive surgery among senior Og/Gyn residents. JSLS. 2009;13(4):473-8.

18. Einarsson Jl, Timmins A, Young AE, Zurawin RK. Does a minimally invasive surgery fellowship impact surgical experience among gynecology residents? J Am Assoc Gynecol Laparosc. 2004;11(4):464-6.

19. Meyerson SL, Sternbach JM, Zwischenberger JB, Bender EM. The effect of gender on resident autonomy in the operating room. J Surg Educ. 2017; 74(6):111-8.

20. Dune J, Blackwell RH, Griffin A, Taege S, et al. Ready or not? Obstetrics and gynecology resident preparedness for female pelvic medicine and reconstructive surgery training. Female Pelvic Med Reconstr Surg. 2017;23:401-8.

21. Urban RR, Ramzan AA, Doo DW, Galan HL, et al. Fellow perceptions of residency training in obstetrics and gynecology. J Surg Ed. 2019;76(1):93-8.

22. Ito TE, Vargas MV, Moawad GN, Opoku-Anane J, Shu MK, Marfori CQ, Robinson JK 3rd. Minimally invasive hysterectomy for uteri greater than one kilogram. JSLS. 2017;21 (1). https://doi.org/10.4293/JSLS.2016.00098.

23. Vargas MV, Moawad GN, Sievers C, Opoku-Anane J, Marfori CQ, Tyan P, Robinson JK. Feasibility, safety, and prediction of complications for minimally invasive myomectomy in women with large and numerous Myomata. J Minim Invasive Gynecol. 2017;24(2):315-22.

\section{Publisher's Note}

Springer Nature remains neutral with regard to jurisdictional claims in published maps and institutional affiliations.

\section{Ready to submit your research? Choose BMC and benefit from:}

- fast, convenient online submission

- thorough peer review by experienced researchers in your field

- rapid publication on acceptance

- support for research data, including large and complex data types

- gold Open Access which fosters wider collaboration and increased citations

- maximum visibility for your research: over $100 \mathrm{M}$ website views per year

At BMC, research is always in progress.

Learn more biomedcentral.com/submissions 